\title{
Efficacy of radiotherapy on intermediate and advanced lung cancer and its effect on dynamic changes of serum vascular endothelial growth factor and matrix metalloproteinase-9
}

\author{
GUOWEI DING, YONGCHAO LIU and CHUNMEI LIANG \\ Department of Radiotherapy, Tianjin Fifth Central Hospital, Tianjin 300450, P.R. China
}

Received October 3, 2017; Accepted April 20, 2018

DOI: $10.3892 / \mathrm{ol} .2018 .8622$

\begin{abstract}
The present study intended to investigate efficacy of radiotherapy in the treatment of intermediate and advanced stage lung cancer and the effects on serum vascular endothelial growth factor (VEGF) and matrix metalloproteinase-9 (MMP-9). Serum levels of VEGF and MMP-9 of 77 patients with intermediate or advanced lung cancer were detected before and after the treatment. At the same time, 19 healthy people were selected as the control group. Gelatin zymography was applied to measure the activity of serum MMP-9, ELISA was performed to detect the VEGF and MMP-9 levels in the peripheral blood and reverse transcription-quantitative polymerase chain reaction (RT-qPCR) was used to measure the messenger RNA (mRNA) levels of VEGF and MMP-9 in serum. Results indicated that the overall response rate of radiotherapy on intermediate and advanced lung cancer reached $70.1 \%$. Levels of serum VEGF and MMP-9 in the effective treatment group were significantly lower than those before the treatment $(\mathrm{P}<0.05)$. Furthermore, expression levels of VEGF and MMP-9 in the effective radiotherapy group were significantly lower than those in ineffective group $(\mathrm{P}<0.05)$, MMP-9 activity before treatment was significantly higher than that after treatment $(\mathrm{P}<0.05)$ and expression levels of VEGF and MMP-9 mRNA before treatment were significantly elevated compared with those after treatment $(\mathrm{P}<0.05)$. The results suggested that the expression levels of serum VEGF and MMP-9 may be useful indicators for the evaluation of the efficacy of radiotherapy in the treatment of intermediate and advanced lung cancer.
\end{abstract}

\section{Introduction}

Up to now, radiotherapy still the main treatment for $\mathrm{f}$ patients with intermediate or advanced lung cancer or patient who

Correspondence to: Dr Guowei Ding, Department of Radiotherapy, Tianjin Fifth Central Hospital, 41 Zhejiang Road, Tianjin 300450, P.R. China

E-mail: dg50qg@163.com

Key words: intermediate and advanced lung cancer, vascular endothelial growth factor, matrix metalloproteinase-9 cannot tolerate surgical treatments (1). Vascular endothelial growth factor (VEGF), as the strongest pro-angiogenic factor, can increase vascular permeability, provide nutrients for growth of tumor cells and promote development of tumor (2). In the body, matrix metalloproteinases (MMPs) can degrade extracellular matrix as well as major components of basement membrane, and participate in inflammatory responses (2), atherosclerosis (3), tumor infiltration and metastasis (4) and many other physiological and pathological processes. In this study, enzyme-linked immunosorbent assay (ELISA) was performed to detect VEGF and MMP-9 levels in peripheral blood; reverse transcription-quantitative polymerase chain reaction (RT-qPCR) was used to detect the expression of related genes at messenger RNA (mRNA) level; gelatin zymography was applied to measure the activity of serum MMP-9. Finally, the feasibility of the application as indicators for the evaluation of efficacy of radiotherapy in the treatment of intermediate and advanced lung cancer were discussed.

\section{Materials and methods}

General information. A total of 77 patients who were diagnosed with non-small cell lung cancer in the intermediate or advanced stage in Tianjin Fifth Central Hospital (Tianjin, China) from February 2016 to February 2017 were selected as experimental group. The inclusion criteria were: i) Patients with non-small cell lung cancer confirmed with pathologic examination; ii) patients with measurable tumor lesions and without surgery indications; iii) patients with the disease in intermediate or advanced stage, namely, with a tumor-node-metastasis (TNM) stage of III-IV; iv) patients with a survival time $>3$ months; and v) patients without radiotherapy contraindications as well as hematological system and autoimmune diseases but were normal in blood routine tests and with normal hepatic or renal functions. Among those patients, 53 were males and 24 were females, and the mean age was $55.24 \pm 8.83$ years old. A total of 19 healthy (12 males and 7 females) people were selected at the same time to serve as control group, and the mean age was $56.15 \pm 6.94$ years old. There were no significant differences in gender, age and other basic data between controls and patients $(\mathrm{P}>0.05)$. This experiment was approved by the Ethics Committee of the Tianjin Fifth Central Hospital, and informed consent was signed by all the patients and their families. 
Experimental reagents and instruments. ELISA kits for human VEGF and MMP-9 (Beijing KERUI MEI Technology Co., Ltd., Beijing, China); gelatin zymography kits (BestBio, Shanghai, China); RT kit (Shenzhen Abaier Biotech Co., Ltd., Shenzhen, China); gelatin zymography kits (Shanghai Xinfan Biotech Co., Ltd., Shanghai, China); automatic microplate reader (Shanghai Utrao Medical Instrument Co., Ltd., Shanghai, China); centrifuge (Thermo Fisher Scientific, Inc., Waltham, MA, USA); pipette (Eppendorf, Hamburg, Germany).

\section{Experimental methods}

Radiotherapy. Computed tomography (CT) simulation was applied to measure gross tumor volume (GTV) and organs at risk; GTV was equably expanded by $6-8 \mathrm{~mm}$ to obtain a clinical target volume which was further expanded flatly by $5 \mathrm{~mm}$ and vertically by $10 \mathrm{~mm}$ to make a planning target volume (PTV); then the expanded PTV was modified appropriately if it included the spinal cord tissues. Simultaneously integrated boost technology (SIB) was utilized, with a prescribed dose of PTV (50-66 Gy), which was given at a dose of 1.8-2.0 Gy/day for 5 days/week and 25 times (a course of treatment). All patients received a course of treatment with radiotherapy.

Detection of expression levels of serum VEGF and MMP-9. Peripheral blood samples were collected from each patient at 1 day before and 1 day after treatment; expression levels of serum VEGF and MMP-9 were detected according to the instructions of the kit. Antigens were properly diluted with coating buffer to make final concentration of $10 \mathrm{mg} / \mathrm{ml} ; 100 \mu 1$ solution was added into each well and incubated at $37^{\circ} \mathrm{C}$ for $1 \mathrm{~h}$; then the plate was placed in a refrigerator at $4^{\circ} \mathrm{C}$ overnight. Then liquid was removed and washing was performed 3 times using $200 \mu \mathrm{l}$ washing solution each time; finally, plate was inverted and the liquid was removed using absorbent paper. Then, $200 \mu \mathrm{l}$ blocking buffer was added and placed at $37^{\circ} \mathrm{C}$ for $1 \mathrm{~h}$. Serum samples to be detected were diluted with a ratio of 1:1,000, 1:2,000, 1:4,000, 1:6,000, 1:8,000, 1:10,000, $1: 20,000,1: 40,000$ and 1:80,000, respectively, and $100 \mu 1$ of diluted serum sample was added into each well. Meanwhile, control samples were also diluted, and negative control was diluted with a ratio of $\mathrm{t} 1: 1,000$. After incubation at $37^{\circ} \mathrm{C}$ for $2 \mathrm{~h} .100 \mu \mathrm{l}$ of horseradish peroxidase-labeled goat-anti-mouse immunoglobulin $\mathrm{G}(\mathrm{IgG})$ was added into each well, followed by incubation at $37^{\circ} \mathrm{C}$ for $1 \mathrm{~h}$. After that, washing was performed twice using double-distilled $\mathrm{H}_{2} \mathrm{O}\left(\mathrm{ddH}_{2} \mathrm{O}\right)$. Then $100 \mu \mathrm{l}$ of 3,3',5,5'-tetramethylbenzidine (TMB) application solution was added into each well and kept in dark for 10-20 min until blue staining appeared. Then, $50 \mu 1$ of stop buffer was added into each well and incubated for 3-5 min. Enzyme-linked immunometric meter was used to measure the OD value at the wavelength of $490 \mathrm{~nm}$. Standard curves were constructed to calculate the contents of serum VEGF and MMP-9.

Response evaluation and observation indexes. CT was performed before and after radiotherapy to evaluate the efficacies of the radiotherapy at 1, 3 and 5 weeks after treatment; short-term efficacy on intermediate and advanced lung cancer was evaluated according to Response Evaluation Criteria in Solid Tumors (RECIST) (5), which was characterized by the
Table I. Primer sequences.

\begin{tabular}{lc}
\hline Gene & Primer \\
\hline MMP-9 & F: 5'-AAGGATGGTCTACTGGCAC-3' \\
& R: 5'-TCAGAACCGACCCTACAA-3' \\
VEGF & F:5'-TCGGGCCTCCGAAACCATGA-3' \\
& R:5'-CCTGGAGAGAGATCTGGTTC-3' \\
GAPDH & F: 5'-TGGGTGTGAACCACGAGAA-3' \\
& R:5'-GGCATGGACTGTGGTCATGA-3'
\end{tabular}

F, forward; R, reverse; MMP, matrix metalloproteinase; VEGF, vascular endothelial growth factor.

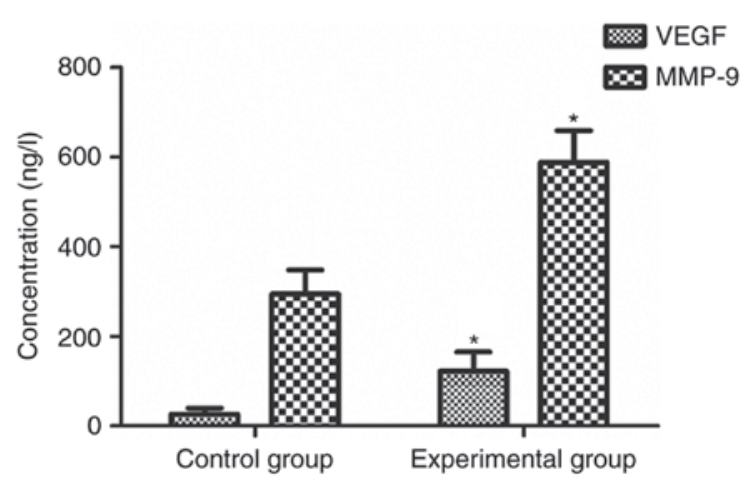

Figure 1. Comparisons of serum VEGF and MMP-9 between control group and experimental group before the treatment. The results of ELISA show that the serum VEGF and MMP-9 levels in experimental group before treatment are obviously higher than those in control group. ${ }^{*} \mathrm{P}<0.05$ compared with that in control group. MMP, matrix metalloproteinase; VEGF, vascular endothelial growth factor.

tumor size measured via double-path product method. Changes in tumor size before and after the treatment were compared. Efficacy was mainly divided into 4 levels, namely, complete remission (CR), partial remission (PR), stable disease (SD) and progressive disease (PD); $\mathrm{CR}+\mathrm{PR}$ represented effective treatment and $\mathrm{SD}+\mathrm{PD}$ represented $\mathrm{PD}$.

Detection of MMP-9 activity. In this study, gelatin zymography kit was utilized to detect MMP-9 activity in peripheral blood serum. Frozen serum was placed at room temperature for equilibrium; $20 \mu \mathrm{l}$ serum was mixed with $20 \mu \mathrm{l}$ loading buffer through vortex oscillation. Then, the mixture was subjected to $10 \%$ acrylamide gel electrophoresis. After staining and washing, white bands appeared. Optical density value of the white band indicated enzyme activity.

Detection of mRNA expressions via RT-qPCR. Primers were synthesized by FamilyLab International Biological Technology Institute Ltd. (Beijing, China), the primer sequences were listed in Table I. Total RNA in serum was extracted according to the instructions of RNA extraction kit, and the complementary DNA (cDNA) was synthesized using RT kit.

$20 \mu \mathrm{l}$ RT system: $4 \mu 1$ 5X PrimeScript Buffer, $1 \mu 1$ Random 6 mers $(100 \mu \mathrm{M}), 1 \mu \mathrm{l}$ Oligo dT Primer $(50 \mu \mathrm{M})$, $1 \mu \mathrm{l}$ PrimeScipt RT Enzyme Mix, $3 \mu \mathrm{l}$ total RNA and $10 \mu \mathrm{l}$ 



Figure 2. Correlation between serum VEGF level and efficacy. Serum levels of VEGF in patients of effective treatment group were significantly lower than those before treatment at 1,3 and 5 weeks after treatment $(\mathrm{P}<0.05)$. For patients with tumors in advanced stage, there were no notable changes in the serum VEGF levels after radiotherapy. ${ }^{* *} \mathrm{P}<0.05$ compared with pretreatment level. VEGF, vascular endothelial growth factor.


Figure 3. Correlation between serum MMP-9 level and efficacy. Serum levels of MMP-9 in patients of effective treatment group were significantly lower than those before treatment at 1,3 and 5 weeks after treatment $(\mathrm{P}<0.05)$. For patients with tumors in advanced stage, there were no notable changes in the serum MMP-9 levels after radiotherapy. ${ }^{* *} \mathrm{P}<0.05$ compared with pretreatment level. MMP, matrix metalloproteinase.

ribonuclease (RNase) Free $\mathrm{dH}_{2} \mathrm{O}$. Reaction conditions for $\mathrm{RT}$ : $37^{\circ} \mathrm{C}$ for $15 \mathrm{~min}$ and $85^{\circ} \mathrm{C}$ for $5 \mathrm{sec}$.

$25 \mu 1$ PCR system: $12.5 \mu 1$ SYBR Premix Ex $\mathrm{Taq}^{\mathrm{TM}} \mathrm{II}$, $1 \mu \mathrm{l}$ forward primer, $1 \mu \mathrm{l}$ reverse primer, $2 \mu \mathrm{l} \mathrm{cDNA}$ and

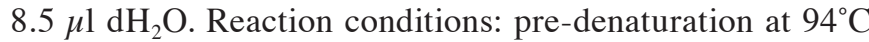
for $3 \mathrm{~min}$, followed by 40 cycles of denaturation at $94^{\circ} \mathrm{C}$ for $20 \mathrm{sec}$, annealing at $58^{\circ} \mathrm{C}$ for $20 \mathrm{sec}$ and extension at $72^{\circ} \mathrm{C}$ for $30 \mathrm{sec}$. With GAPDH asendogenous control, relative expression levels of MMP-9 and VEGF mRNAs were automatically calculated using by RT-qPCR instrument.

Statistical analysis. Statistical Product and Service Solutions (SPSS) 17.0 software (Beijing Xinmei Jiahong Technology Co., Ltd., Beijing, China) was used for all statistical analyses. Measurement data were expressed as mean \pm standard deviation; t-test was used for comparisons between two groups, paired t-test was performed for intragroup comparisons, and one-way analysis of variance (ANOVA) was used for comparisons among multiple groups followed by the SNK post hoc test. Count data were processed using $\chi^{2}$ test, and $\alpha=0.05$ was regarded as the statistical standard.

\section{Results}

Comparisons of serum level of VEGF and MMP-9 between two groups. Results of ELISA showed that, compared with normal control group, significantly higher levels of VEGF and MMP-9 were found in experimental group ( $\mathrm{P}<0.05$; Fig. 1).

Correlation between serum level of VEGF and MMP-9 and efficacy in experimental group. According to the efficacy evaluation after treatment, there were 19 cases of $\mathrm{CR}, 35$ cases of PR, 16 cases of SD and 7 cases of PD; the effective rate of treatment $(\mathrm{CR}+\mathrm{PR})$ was $70.1 \%$. Serum levels of VEGF and MMP-9 in patients of effective treatment group were significantly lower than those before treatment at 1, 3 and 5 weeks after treatment $(\mathrm{P}<0.05)$. For patients with tumors in advanced stage, namely, patients in SD+PD stage, there were no notable changes in the serum VEGF and MMP-9 levels after radiotherapy (Figs. 2 and 3).

Correlation of radiotherapy efficacy with serum VEGF and MMP-9 before and after treatment. Before radiotherapy, serum VEGF level of the patients in effective group was $94.13 \pm 38.35 \mathrm{ng} / \mathrm{l}$, and that in progressive group was $138.22 \pm 45.05 \mathrm{ng} / 1$, there was no statistically significant difference between those two groups $(\mathrm{P}>0.05)$. After radiotherapy, serum VEGF level of the patients in effective group was $50.28 \pm 33.17 \mathrm{ng} / \mathrm{l}$, while that in progressive group was $127.36 \pm 52.84 \mathrm{ng} / \mathrm{l}$, the difference between the two groups was statistically significant ( $\mathrm{P}<0.05$; Fig. 4A).

Before radiotherapy, serum MMP-9 level of the patients in effective group was $495.05 \pm 81.17 \mathrm{ng} / \mathrm{l}$, and that in progressive group was $601.53 \pm 70.05 \mathrm{ng} / \mathrm{l}$, there was no statistically significant difference between two groups $(\mathrm{P}>0.05)$. After radiotherapy, serum MMP-9 level of the patients in effective group was $340.25 \pm 68.93 \mathrm{ng} / \mathrm{l}$, while that in progressive group was $579.95 \pm 82.24 \mathrm{ng} / \mathrm{l}$, the difference between the two groups was statistically significant $(\mathrm{P}<0.05$; Fig. 4B).

MMP-9 activity in peripheral blood serum. Compared with control group, significantly higher MMP-9 activity was 
Table II. Comparisons of MMP-9 activity in peripheral blood serum (mean \pm standard deviation).

\begin{tabular}{lccccc}
\hline & & \multicolumn{2}{c}{ Net optical density } & & \\
\cline { 3 - 5 } Group & Case $(\mathrm{n})$ & Effective & Progressive & $\mathrm{t}$ & $\mathrm{P}$ \\
\hline Control group & 19 & $2.83 \pm 0.76$ & & -3.617 & $<0.05$ \\
Before treatment & 77 & $25.56 \pm 5.28$ & $27.02 \pm 5.74$ & & \\
After treatment & 77 & $14.92 \pm 3.88$ & $24.03 \pm 4.95$ & & \\
\hline
\end{tabular}

MMP, matrix metalloproteinase.
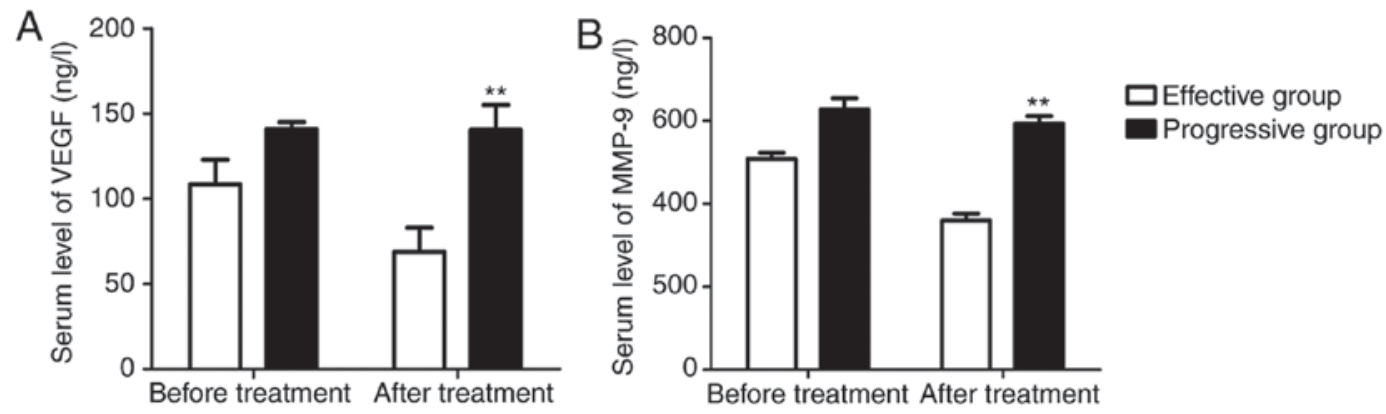

Figure 4. Correlation of radiotherapy efficacy with serum VEGF and MMP-9 before and after treatment. (A) No significant difference in serum level of VEGF was found between effective group and progressive group before treatment $(\mathrm{P}>0.05)$. Significant difference in serum level of VEGF was found between effective group and progressive group after treatment $(\mathrm{P}<0.05)$. (B) No significant difference in serum level of MMP-9 was found between effective group and progressive group before treatment $(\mathrm{P}>0.05)$. Significant difference in serum level of MMP-9 was found between effective group and progressive group after treatment $(\mathrm{P}<0.05) .{ }^{* *} \mathrm{P}<0.05$ compared with effective group. MMP, matrix metalloproteinase; VEGF, vascular endothelial growth factor.


Figure 5. VEGF and MMP-9 mRNA expression. Compared with control group, significantly higher expression levels of VEGF and MMP-9 mRNA were detected in patients both before and after treatment. Expression levels of VEGF and MMP-9 mRNA after treatment were significantly lower than those before treatment. ${ }^{* *} \mathrm{P}<0.05$ compared with control group. MMP, matrix metalloproteinase; VEGF, vascular endothelial growth factor.

detected in patients both before and after treatment $(\mathrm{P}<0.05)$. MMP-9 activity after treatment was significantly lower than that before treatment $(\mathrm{P}<0.05$; Table II).

VEGF and MMP-9 mRNA expressions. Compared with control group, significantly higher expression levels of VEGF and MMP-9 mRNAs were detected in patients both before and after treatment $(\mathrm{P}<0.05)$. Expression levels of VEGF and
MMP-9 after treatment were significantly lower than those before treatment $(\mathrm{P}<0.05$; Fig. 5).

\section{Discussion}

With the increased severity of air pollution, incidence rate of lung cancer is increasing year by year (6). More than $70 \%$ of the lung cancer patients were diagnosed at intermediate and 
advanced stage (7). As one of the major methods in the treatment of intermediate and advanced lung cancer, radiotherapy can effectively kill tumor cells and prolong the patients' survival time (8).

VEGF has multiple biological effects in the human body. VEGF expression is significantly up-regulated in tumor cells, and the expression level is closely related to the infiltration, metastasis and prognosis of the tumor cells (9). Under hypoxia, VEGF expression is up-regulated. After binding to its receptors, VEGF can accelerate endothelial cell division, increase production of blood vessels and lymphatic vessels, so as to promote growth, infiltration and metastasis the tumor cells (10-12). In recent years, VEGF has become a new target for the inhibition of tumor vascularization (13). Some studies have shown that expression levels of VEGF, carcinoembryonic antigen (CEA) and neuron-specific enolase (NSE) in the serum were positively correlated with cancer stage (14). MMP-9 is a member of the MMP family. It was reported that MMP-9 and tissue inhibitor of metalloproteinases 1 (TIMP1) were highly expressed in serum of lung cancer patients compared with normal healthy people (15). Expression levels of MMP-9 and TIMP1 in stages III and IV were obviously higher than those in stages I and II, indicating that expressions levels of TIMP1 and MMP-9 in the serum were closely correlated with the occurrence and development of lung cancer (16). Some studies have revealed that MMP-9 plays an important role in the occurrence and development of tumor infiltration and metastasis (17), possibly due to the positive correlation between expression of VEGF and MMP-9 in tumor cells. In addition, MMP-9 can interact with connective tissue growth factor to inhibit its binding to VEGF receptors, as a result, more VEGF will be released, and the formation of tumor neovascularization will be promoted (18).

In this study, ELISA was used to detect the VEGF and MMP-9 levels in the peripheral blood, enzyme activity test was performed, and RT-qPCR method were applied to measure mRNA expressions. Results showed that the overall response rate of radiotherapy on intermediate and advanced lung cancer reached $70.1 \%$. Levels of serum VEGF and MMP-9 in effective treatment group were obviously lower than those before treatment $(\mathrm{P}<0.05)$; meanwhile, expression levels of VEGF and MMP-9 in effective radiotherapy group were obviously lower than those in progressive group $(\mathrm{P}<0.05)$. MMP-9 activity before treatment was remarkably higher than that after treatment $(\mathrm{P}<0.05)$. Expression levels of VEGF and MMP-9 mRNA before treatment were evidently elevated compared with those after treatment $(\mathrm{P}<0.05)$. Our finding were consistent with the role of MMP-9 in lung cancer reported by previous studies $(19,20)$. Our study further proved that VEGF and MMP-9 can be used as indicators for the evaluation of efficacy of radiotherapy in the treatment of intermediate and advanced lung cancer (21). However, our study is still limited by the small sample size. Further studies with bigger sample size are needed to confirm the conclusions in this study.

In conclusion, VEGF and MMP-9 expression levels in intermediate and advanced lung cancer decreased significantly after radiotherapy. Detection of serum VEGF and MMP-9 expressions can be used as novel indicators for the evaluation of efficacy of radiotherapy in the treatment of intermediate and advanced lung cancer.

\section{Acknowledgements}

Not applicable.

Funding

No funding was received.

\section{Availability of data and materials}

The datasets used and/or analyzed during the current study are available from the corresponding author on reasonable request.

\section{Authors' contributions}

GD and YL analyzed and interpreted the patient data. GD wrote the manuscript. CL collected the patient data and revised the manuscript for important intellectual content. GD and CL contributed to the conception and design of the study. All authors read and approved the final manuscript.

\section{Ethics approval and consent to participate}

This study was approved by the ethics committee of the Tianjin Fifth Central Hospital. Patients who participated in this research, signed the informed consent.

\section{Consent for publication}

Not applicable.

\section{Competing interests}

The authors declare that they have no competing interests.

\section{References}

1. Hayano K, Kulkarni NM, Duda DG, Heist RS and Sahani DV: Exploration of imaging biomarkers for predicting survival of patients with advanced non-small cell lung cancer treated with antiangiogenic chemotherapy. AJR Am J Roentgenol 206: 987-993, 2016

2. Kim A, Im M, Yim NH and Ma JY: Reduction of metastatic and angiogenic potency of malignant cancer by Eupatorium fortunei via suppression of MMP-9 activity and VEGF production. Sci Rep 4: 6994, 2014.

3. Cai J, Li R, Xu X, Zhang L, Wu S, Yang T, Fang L, Wu J, Zhu X, Li $\mathrm{M}$ and Huang Y: URGCP promotes non-small cell lung cancer invasiveness by activating the NF- $\mathrm{KB}-\mathrm{MMP}-9$ pathway. Oncotarget 6: 36489-36504, 2015.

4. Liu F and Zhu L: Expression of adiponectin in non-small cell lung cancer and its relationship with MMP-9 and angiogenesis. Zhong Nan Da Xue Xue Bao Yi Xue Ban 40: 579-584, 2015 (In Chinese).

5. Lin X, Li HR, Lin XF, Yu ME, Tu XW, Hua ZD, Lin M, Xu NL, Han LL and Chen YS: Silencing of Livin inhibits tumorigenesis and metastasis via VEGF and MMPs pathway in lung cancer. Int J Oncol 47: 657-667, 2015.

6. El-Badrawy MK, Yousef AM, Shaalan D and Elsamanoudy AZ: Matrix metalloproteinase-9 expression in lung cancer patients and its relation to serum mmp-9 activity, pathologic type, and prognosis. J Bronchology Interv Pulmonol 21: 327-334, 2014.

7. Ramanujum R, Lin YL, Liu JK and He S: Regulatory expression of MMP-8/MMP-9 and inhibition of proliferation, migration and invasion in human lung cancer A549 cells in the presence of HGF variants. Kaohsiung J Med Sci 29: $530-539,2013$ 
8. Matsumoto Y, Zhang Q, Akita K, Nakada H, Hamamura K, Tsuchida A, Okajima T, Furukawa K, Urano T and Furukawa K: Trimeric Tn antigen on syndecan 1 produced by ppGalNAc-T13 enhances cancer metastasis via a complex formation with integrin $\alpha 5 \beta 1$ and matrix metalloproteinase 9. J Biol Chem 288: 24264-24276, 2013.

9. Xu T, Xu Y, Huo J, Yang P, Gomez DR and Liao Z: Incidental use of beta-blockers, serum VEGF, and their association with disease outcome in patients with non-small-cell lung cancer treated with definitive chemoradiation therapy. Int J Radiat Oncol Biol Phys 98: 245, 2017.

10. Zhang H, Yun S, Batuwangala TD, Steward M, Holmes SD, Pan L, Tighiouart M, Shin HJ, Koenig L, Park W, et al: A dual-targeting antibody against EGFR-VEGF for lung and head and neck cancer treatment. Int J Cancer 131: 956-969, 2012.

11. Zheng $\mathrm{H}$ and Liu JF: Studies on the relationship between P13K/AKT signal pathway-mediated MMP-9 gene and lung cancer. Eur Rev Med Pharmacol Sci 21: 753-759, 2017.

12. Farhat FS, Tfayli A, Fakhruddin N, Mahfouz R, Otrock ZK, Alameddine RS, Awada AH and Shamseddine A: Expression, prognostic and predictive impact of VEGF and bFGF in non-small cell lung cancer. Crit Rev Oncol Hematol 84: 149-160, 2012.

13. Kerenidi T, Kazakou AP, Lada M, Tsilioni I, Daniil Z and Gourgoulianis KI: Clinical significance of circulating osteopontin levels in patients with lung cancer and correlation with VEGF and MMP-9. Cancer Invest 34: 385-392, 2016.

14. Shiau MY, Fan LC, Yang SC, Tsao CH, Lee H, Cheng YW, Lai LC and Chang YH: Human papillomavirus up-regulates MMP-2 and MMP-9 expression and activity by inducing interleukin-8 in lung adenocarcinomas. PLoS One 8: e54423, 2013.

15. Yeo CD, Kim YA, Lee HY, Kim JW, Lee SH, Kim SJ, Kwon SS Kim YH and Kim SC: Inhibiting IGF-1R attenuates cell proliferation and VEGF production in IGF-1R over-expressing EGFR mutant non-small cell lung cancer cells. Exp Lung Res 43: 29-37, 2017.
16. Peng WJ, Zhang JQ, Wang BX, Pan HF, Lu MM and Wang J: Prognostic value of matrix metalloproteinase 9 expression in patients with non-small cell lung cancer. Clin Chim Acta 413: 1121-1126, 2012.

17. Fan Z, Duan X, Cai H, Wang L, Li M, Qu J, Li W, Wang Y and Wang J: Curcumin inhibits the invasion of lung cancer cells by modulating the PKC $\alpha$ /Nox-2/ROS/ATF-2/MMP-9 signaling pathway. Oncol Rep 34: 691-698, 2015.

18. Ye HJ, Bai JJ, Guo PP, Wang W and Lin CS: Propofol suppresses invasion of human lung cancer A549 cells by down-regulating aquaporin-3 and matrix metalloproteinase-9. Nan Fang Yi Ke Da Xue Xue Bao 36: 1286-1290, 2016 (In Chinese).

19. Xu L, Lina W and Xuejun Y: The diagnostic value of serum CEA, NSE and MMP-9 for on-small cell lung cancer. Open Med (Wars) 11: 59-62, 2016.

20. Lee CY, Shim HS, Lee S, Lee JG, Kim DJ and Chung KY: Prognostic effect of matrix metalloproteinase-9 in patients with resected Non-small cell lung cancer. J Cardiothorac Surg 10: 44 , 2015.

21. Balla MM, Desai S, Purwar P, Kumar A, Bhandarkar P, Shejul YK, Pramesh CS, Laskar S and Pandey BN: Differential diagnosis of lung cancer, its metastasis and chronic obstructive pulmonary disease based on serum Vegf, Il-8 and MMP-9. Sci Rep 6: 36065, 2016.

This work is licensed under a Creative Commons Attribution-NonCommercial-NoDerivatives 4.0 International (CC BY-NC-ND 4.0) License. 